\title{
A review of investigations into adenotonsillectomy
}

\author{
G. A. VENTERS AND M. J. BLOOR \\ South East of Scotland Regional Hospital Board, Edinburgh, and MRC Medical Sociology Unit, Aberdeen
}

\section{SUMMARY}

Operations on the tonsils and adenoids are among the most commonly performed of all operations but present a wide range of problems when attempts are made to evaluate the results. This article reviews the findings of the major evaluative studies and discusses the general difficulties that confront them, particularly those that arise from failure to take into account the extensive web of social factors that precipitate a child towards operation and colour interpretation of symptomatology. It suggests that, while variations in operation rate persist on a geographic basis, variations according to social class have almost disappeared.

\section{INTRODUCTION}

Although operations on the tonsil have an ancient history (Celsus (translated), 1938) it is only in the last century that such procedures became common practice. Introduction of adenoidectomy (Meyer, 1870) led to a rapid increase in the frequency of operations on the upper respiratory tract, and the combination of adenoidectomy and tonsillectomyTs and As-came to be one of the commonest operations performed on children. This rapidity of increase was a matter of concern to many otolaryngologists and was a major factor contributing to the initiation of studies into the value of such operations. The purpose of this paper is to examine some of the more important difficulties encountered in such studies in the hope that a clear appreciation of their nature will facilitate valid and valuable research into operations on the tonsils and adenoids.

\section{Problems in Evaluation}

The aim of any therapeutic intervention is to improve the condition of the patient. Evaluation of the effectiveness of a procedure will be in terms of measurement of improvement that can be attributed solely to that procedure. Attempts to evaluate adenoidectomy and tonsillectomy have been made in different ways. The nature of these attempts and the problems associated with them are discussed below.

\section{INDICATIONS FOR OPERATION}

The initial step in any evaluation is to identify those indications for which the procedure may be appropriate. Layton (1914) provided a basic statement of these which can be considered valid today: 'The two indications for removing the tonsils, faucial or pharyngeal, are because they are the seat of some inflammatory lesion or because they are causing some mechanical obstruction to the function of the nose, mouth or ear'. Such criteria, though logically justifiable, suffer from the defect that they are not unequivocal. The degree of severity of an inflammatory lesion or of mechanical obstruction that might benefit from operation is a matter of clinical judgement. Different consultants may have different criteria for deciding on operation and may vary in their assessment of the same patient.

More recent attempts to define valid indications have been made by Fry (1957) and Illingworth (1961). Both cited indications similar to those of Layton, Illingworth specifying in some detail what inflammatory or obstructive conditions can be expected to benefit from operation. He concluded that adenoids should be removed only if a large adenoidal pad was present and there was postnasal obstruction, recurrent otitis media, nasal speech, or postnasal discharge in the absence of antral infection. Tonsillectomy, he considered, was indicated when there were frequent attacks of tonsillitis uncontrollable by prophylactic antibiotics.

\section{Evaluative Studies}

Investigations attempting to evaluate the general worth of adenoidectomy and tonsillectomy have been less restrictive in their list of indications for which the operation might be undertaken and the major studies are summarized in Table $I$. They have followed two main methods: 
EVALUATIVE STUDIES OF ADENOTONSILLECTOMY

\begin{tabular}{|c|c|c|c|}
\hline Study & Nature & Conclusions & Problems in Evaluation \\
\hline Kaiser (1922) & $\begin{array}{l}\text { Evaluation of postoperative health } \\
\text { of child with that before operation }\end{array}$ & $\begin{array}{l}\text { Operation beneficial for many, but } \\
\text { not all, commonly accepted } \\
\text { indications }\end{array}$ & No control group \\
\hline Kaiser (1931) & $\begin{array}{l}\text { Comparison of illness occurring in } \\
\text { children with similar indications, } \\
\text { grouped as to whether or not they } \\
\text { received operation }\end{array}$ & $\begin{array}{l}\text { Operation beneficial for many, but } \\
\text { not all, commonly accepted } \\
\text { indications }\end{array}$ & $\begin{array}{l}\text { Self-selected control group. Reliance } \\
\text { on parental recall. Statistical problems }\end{array}$ \\
\hline $\begin{array}{l}\text { Glover and Wilson } \\
\text { (1932) }\end{array}$ & $\begin{array}{l}\text { Comparison of health of adeno- } \\
\text { tonsillectomized with that of } \\
\text { normal non-tonsillectomized child- } \\
\text { ren }\end{array}$ & $\begin{array}{l}\text { Operation of dubious value in the } \\
\text { majority of cases }\end{array}$ & $\begin{array}{l}\text { Basis for comparison of tonsillecto- } \\
\text { mized population with controls is } \\
\text { inadequate }\end{array}$ \\
\hline $\begin{array}{l}\text { Epidemics in } \\
\text { Schools (1938) }\end{array}$ & $\begin{array}{l}\text { Frequency of infection in school } \\
\text { epidemics of adenotonsillecto- } \\
\text { mized children compared with that } \\
\text { of 'normal' (i.e., non-tonsillecto- } \\
\text { mized) children }\end{array}$ & $\begin{array}{l}\text { Operation of dubious value in the } \\
\text { majority of cases }\end{array}$ & $\begin{array}{l}\text { Basis for comparison of ton- } \\
\text { sillectomized population with controls } \\
\text { is inadequate }\end{array}$ \\
\hline Meitz (1954) & $\begin{array}{l}\text { Comparison of health of adeno- } \\
\text { tonsillectomized with that of non- } \\
\text { tonsillectomized children }\end{array}$ & $\begin{array}{l}\text { No improvement in upper respira- } \\
\text { tory infection. Reduction in } \\
\text { frequency of 'tonsillitis' }\end{array}$ & $\begin{array}{l}\text { Basis for comparison of tonsillecto- } \\
\text { mized population with controls is } \\
\text { inadequate }\end{array}$ \\
\hline McCorkle et al (1955) & $\begin{array}{l}\text { Very accurate assessment of illness } \\
\text { experience in adenotonsillecto- } \\
\text { mized and non-tonsillectomized } \\
\text { individuals }\end{array}$ & Operation of dubious value & $\begin{array}{l}\text { Basis for comparison of tonsillecto- } \\
\text { mized population with controls is } \\
\text { inadequate }\end{array}$ \\
\hline McKee $(1963 a, b)$ & $\begin{array}{l}\text { Prospective study of children with } \\
\text { non-urgent indications allocated at } \\
\text { random to adenoidectomy and } \\
\text { tonsillectomy and non-tonsillect- } \\
\text { omy groups }\end{array}$ & $\begin{array}{l}\text { Operation of value for recurrent } \\
\text { pharyngitis and otitis media }\end{array}$ & $\begin{array}{l}\text { Assessment based on parental recall. } \\
\text { Children for whom operation was } \\
\text { essential omitted from study }\end{array}$ \\
\hline $\begin{array}{l}\text { Mawson et al. } \\
\quad(1967,1968)\end{array}$ & Similar to McKee (1963) & $\begin{array}{l}\text { Operation of value for recurrent } \\
\text { pharyngitis. Not for otitis media }\end{array}$ & $\begin{array}{l}\text { Follow-up again based on parentat } \\
\text { recall and requiring attendance at } \\
\text { clinics. Cases requiring operation } \\
\text { urgently excluded from study }\end{array}$ \\
\hline Roydhouse (1969) & $\begin{array}{l}\text { Comparison of illness experience } \\
\text { of children randomly receiving } \\
\text { adenotonsillectomy with that of } \\
\text { those who do not, also a random } \\
\text { sample of the healthy operation }\end{array}$ & Operation of value & $\begin{array}{l}\text { Data obtained from parents whose } \\
\text { biases could modify their response }\end{array}$ \\
\hline
\end{tabular}

(1) comparisons of the pre- and post-operative health or illness experience of the child for whom adenotonsillectomy has been performed. Control groups may or may not have been used in such studies:

(2) prospective studies of children with similar indications for operation allocated at random to comparable groups differing only in whether or not they received operation.

The earliest studies adopted the first methodological orientation. Kaiser (1922) pioneered the first major evaluative study of adenotonsillectomy. He compared the postoperative illness experience of 5,000 children with their preoperative health and came to the conclusion that the operation was of value in reducing the frequency of colds and sore throats, and improving the general health of the child. In this initial study he provided no comparable control population and, as children are less prone to experience conditions predisposing to operation as they grow older (Evans, 1968), it is impossible to determine from such a pre- or post-operative comparison whether or not the operation is beneficial. The major merit of this study was that it attempted to define valid clinical indications for the operation and was a serious attempt to measure benefit when adenotonsillectomy was fast becoming considered as 'a panacea for all the ills of a child whose tonsils project beyond the anterior pillar of his fauces' (Layton, 1914).

Kaiser later (1931) reported on a study of the change in frequency of occurrence of conditions predisposing to tonsillectomy at intervals of one, three, and five years postoperatively in a group of children undergoing adenotonsillectomy. He used a 'control' group for comparison but the validity of this is open to doubt as the group was derived from children who were suffering from similar conditions 
to those operated upon but, for a number of reasons, did not receive operation. The major reason for control children not receiving operation was parental objection to it. As the bulk of data on the child's medical history was derived from parents, their attitudes to the value of operation may well have influenced their assessment of medical symptomatology experienced by the child. A further factor tending to limit the value of his findings is the lack of adequate statistical analysis of his data.

Almost contemporaneously with Kaiser's investigation, Glover and Wilson (1932) approached the problem from another standpoint. Finding little difference in illness experience between boarding school children who had received operation and those who had not, they considered that adenotonsillectomy conferred no real benefits on the majority of its recipients. Epidemics in Schools (1938) reached the same conclusion, and subsequent similar American studies by Mertz (1954) and McCorkle et al. (1955) tended to support this view. However, the validity of this conclusion is open to the objection that the similarity in illness experience between the two groups might result from an historical improvement in the health of the tonsillectomized children as a result of the operation which restored them to a level of health comparable with their non-tonsillectomized 'normal' peers.

Refutation of this 'post hoc' argument is possible only in prospective studies in which children with predisposing conditions are randomly either given operation, or have the operation withheld and are then compared in terms of the frequency with which they experience conditions which constitute indications for operation.

Such studies have been undertaken in Britain in the recent past by McKee (1963 a, b) and Mawson, Adlington, and Evans (1967, 1968). McKee (1963a) selected a population of 413 children from referrals to an ENT clinic. His sample consisted of children for whom the operation was thought to be of equivocal value. They were allocated at random to two groups, one containing those receiving operation, the other, those who did not. He compared the amount of illness encountered in both groups over a two-year period and found that those receiving operation suffered significantly fewer sore throats and less chronic nasal disease and otitis media than the controls. Benefits from the operation appeared to decrease as the age of the recipient increased.

His collection of data on illness experience was by means of bimonthly visits and may have been in error because of the reliance on parental recall, but this source of error ought to be the same for both groups and should not invalidate comparisons. A more serious objection to his parentally derived data is that parents know whether or not the child has had a tonsillectomy, and this knowledge will colour their interpretation of symptomatology. This point is accepted in McKee's paper in terms of the assessment of the influence of tonsillar tags on upper respiratory and pharayngeal infection (McKee, 1963a, p. 64) - 'parents were not told of the existence of such remnants because it was felt that, by drawing attention to this finding, the future illness reports might be prejudiced'. However, he ignores the possibility of such a bias when considering postoperative illness experience. No evaluative study acknowledged this difficulty, yet a leader in the Lancet (1967) emphasizes that the results claimed for tonsillectomy may derive not so much from the operation as from an operation. Omitted from his study were children for whom the operation was considered an urgent necessity and exclusion of this category of patient seriously limits any attempt to evaluate the overall worth of operation.

McKee's (1963b) study of adenoidectomy (which is subject to the same reservations as above) concluded that the operation conferred benefit only in terms of reducing the incidence of otitis media in those undergoing the operation.

A similar evaluative study was undertaken by Mawson et al. $(1967,1968)$ on 404 children (again for whom operation was debatably indicated), and the conclusions are subject to the same reservations regarding the problems associated with parental recall and interpretation of symptoms. His data were obtained at bimonthly intervals at outpatient clinics and his rate of defaulters is higher than that of McKee. The findings also are somewhat different from those of McKee in that while concurring that the incidence of pharyngitis, tonsillitis, and sore throat was reduced in the group receiving operation compared with the controls during the two-year period of study, he also found that the incidence of head colds was reduced. McKee did not find this latter reduction. In addition, the diminution $\mathrm{McKee}$ (1963a) observed in otitis media following the combined operation was not observed in Mawson's study.

The second part of the study by Mawson et al. (1968) was concerned with the evaluation of what are less absolute criteria for adenoidectomy, such as catarrh, cough, mouth breathing, and snoring. Most symptoms appeared to improve after operation with the exception of cough in children under 4 years. Also in this paper he attempts to evaluate changes in symptomatology in children for whom operation could no longer be ethically withheld. The numbers ( 25 patients) are rather small for any 
definite conclusions to be drawn as to how such patients fare as a result of operation but the indication is that the operation is beneficial in reducing the frequency of sore throat in this group.

Roydhouse (1969) attempted to evaluate the illness experience of a group of children receiving adenotonsillectomy at random within one month of referral and of those being placed on the waiting list (which meant, in effect, not receiving the operation for two years). The illness occurring in both groups was compared with that of a similar 'healthy' (i.e., non-referred) control population. His data were obtained from the parents who were given a supply of forms and prepaid envelopes to use to report illness whenever it occurred in the child. This method is so reliant upon parent motivation and evaluation as to completely explain his findings. Illness was greatest in those on the waiting list. Parents of such children have a vested interest in demonstrating how sick their child is to attempt to achieve more definite medical intervention than the limbo of the waiting list. Parents of 'healthy' children have little incentive to participate in such an investigation compared with those on the waiting list or having had the operation, and their disinterest (hence non-reporting) can account for the apparent difference in the health of their children from the other groups.

A more satisfactory approach is the evaluation of the merits of the operation in preventing the occurrence of clinically well established and readily identifiable conditions which are much less liable to subjective bias than sore throat. Such an approach was adopted by Illingworth (1939) when he considered acute nephritis and by Wallace and Smith (1936) when they considered rheumatic fever. Both studies demonstrated that the operation was of no value in preventing the recurrence of such conditions.

An expansion of this approach would be to define clinically discrete new syndromes for which the operation appeared beneficial. This has been achieved to some extent by Noonan (1965), Luke, Mehrizi, Folger, and Rowe (1966), and Levy, Tabakin, Hanson, and Narkewicz (1967), who have identified a syndrome of cor pulmonale and chronic anoxia in infants associated with and resulting from chronic nasopharyngeal obstruction by hypertrophied tonsils and adenoids. This approach is also the one tacitly adopted by Feinstein and Levitt (1970). The implication of their study is that a 'syndrome' can be defined consisting of unreliable maintenance of chemoprophylaxis plus big tonsils with associated increased likelihood of $\beta$-haemolytic streptococcal infection and severe carditis. Diminution of tonsillar size (presumably by surgery), they suggest, should diminish the consequent illness discussed above. The case for this hypothesis remains unproven because theirs is a post hoc ergo propter hoc argument. Even if an association between tonsillar size and subsequent disease were established, the causal responsibility of the enlarged tonsil for this cannot be assumed. Tonsillar enlargement and streptococcal infection (with or without consequent rheumatic fever) may go hand in hand as the result of a deleterious environment.

The inadequacies and contradictions in evaluative studies provide ample scope for justification of opposing attitudes towards the operation. No entirely satisfactory evaluative study has been done, and this is a serious deficiency considering the frequency with which the operation is performed. A major deficiency, in most, if not all, studies has been in their failure to take proper cognizance of, and make provision for, the extensive nexus of social factors surrounding such an operation.

Social factors concerning operation other than parental bias or recall influencing assessment of illness are revealed by epidemiological studies of the operations.

\section{INVESTIGATIONS OF VARIATION IN INCIDENCE OPERATION}

Investigations of variations in incidence of the operation, along selected sociodemographic parameters such as age, sex, area of residence, and parental socio-economic status, have been mainly descriptive, offering only speculative explanations of the reasons for such variation.

VARIATIONS IN INCIDENCE OF OPERATION BY AGE AND SEX

Glover (1948) has argued that the age distribution for the operation is explicable in terms of the tonsils' postulated immunological function. The operation is most commonly performed on children between ages 5 and 7 years. At this age enlargement of the tonsil may be considered a natural response to the increased immunological demands placed on the $N$ child as a result of his increased exposure to other children. This argument receives indirect support from the observations of Fry (1957).

Sex difference in the operations on the tonsil and 0 adenoid have been observed and continue to exist 0

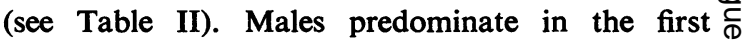
decade of life and females during the second, but $\stackrel{\mathcal{P}}{+}$ the reason for such differences is as yet undeter- 7 mined. Maternal solicitude was postulated by Glover (1948) to be a factor in the difference he 
TABLE II

OPERATIONS ON TONSILS AND ADENOIDS IN SCOTLAND IN 1969 BY AGE AND SEX

\begin{tabular}{|c|c|c|c|c|c|}
\hline \multirow{2}{*}{\multicolumn{2}{|c|}{ Age Group }} & \multicolumn{2}{|c|}{ Males } & \multicolumn{2}{|c|}{ Females } \\
\hline & & No. & Rate/1,000 & No. & Rate $/ 1,000$ \\
\hline $\begin{array}{c}0-4 \\
5-9 \\
10-14 \\
15-19 \\
20-24\end{array}$ & 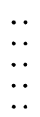 & $\begin{array}{r}3,081 \\
6,673 \\
1,124 \\
458 \\
425\end{array}$ & $\begin{array}{r}13 \cdot 0 \\
27 \cdot 7 \\
5 \cdot 1 \\
2 \cdot 3 \\
2 \cdot 2\end{array}$ & $\begin{array}{r}2,226 \\
6,288 \\
2,081 \\
1,158 \\
563\end{array}$ & $\begin{array}{r}9.9 \\
27.4 \\
10.0 \\
6.0 \\
2.8\end{array}$ \\
\hline
\end{tabular}

observed in rates of operation between boys and girls since 'the boy of five to seven years often looks more skinny and miserable than the girl'. This is the only explanation tendered in recent times of what is an observable but mysterious phenomenon.

Explanations of Regional Variations in OperaTION RATES

Glover (1938) has documented the considerable variations in the operation rate between different areas in the prewar period. These variations have continued since the introduction of the National Health Service (Chief Medical Officer, 1959). Glover did not feel that these differences were attributable, in any marked extent, to any differential incidence of the conditions predisposing to the operation, and subsequent writers (e.g., Fry, 1957 and McKee, 1963a, b) have agreed with him. Indeed, many of the more salubrious areas, where one intuitively would have expected the incidence of predisposing conditions to be relatively low, were areas with the highest operating rates. Thus, in 1956, $38.9 \%$ of school leavers in Bath and $37.5 \%$ of school leavers in Bournemouth had been tonsillectomized, while the equivalent figures in the industrial towns of St. Helens and South Shields were $8 \cdot 6 \%$ and $9.5 \%$ respectively (Chief Medical Officer, 1959).

Glover felt that the differences were explicable in terms of variations in local medical opinion, a point of view that has gained widespread subsequent acceptance (e.g., Fry, 1957). At the time of Glover's investigations the school medical officer had a major role in referring children for consultant opinion and also had direct access to hospital waiting lists in some areas. Since the introduction of the National Health Service, however, the importance of school medical officers as major primary sources of referral has diminished as children now reach hospital mainly through the medium of the family doctor. Consequently, as family doctors and consultants are the arbiters of referral and operation respectively, it is their decisions that are probably of crucial importance in the determination of rates of operation in their localities.

Fry (1957) has argued that GP opinion concerning adenotonsillectomy may be more important in achieving surgical intervention for children than an otolaryngologist's opinion, and some support for this view comes from a study of all outpatient referrals in a Regional Hospital Board area where it was found that $90 \%$ of patients referred with a firm 'tonsils and adenoids' diagnosis were listed for surgery (Backett, Sumner, Kilpatrick, and DingwallFordyce, 1966). One would expect, however, that there would be differences between GPs in their criteria for ENT referral and that these differences would be reflected in differences between GPs in the proportions of their referrals accepted for surgery. Indeed a study in Reading showed considerable variation in the proportion of each GP's outpatient referrals admitted or placed on the waiting list (Oxford Regional Hospital Board Operational Research Unit, No. 3, 1963).

If Fry's hypothesis concerning the importance of the GP in determining case disposals is correct, then it is possible that variations in adenotonsillectomy rates between areas would be explicable in terms of variations in GP opinion concerning the appropriate indications for, and worth of, the operation, which in turn would produce regional variations in referral rates to ENT clinics. As yet, though, despite the large numbers of studies documenting substantial variations between GPs in referral rates to all outpatient clinics-which hold true when referral rates to ENT are considered separately (Forsyth and Logan, 1960)-very little is definitely known about the reasons for these variations and there has been little scrutiny of the relationship between referral rates and attitudinal data on GPs. Even if such a relationship were demonstrated, the question remains why GPs' attitudes to the operation should vary from area to area. If they did, a possible explanation might be that they 'learned' from contacts with local consultants what were acceptable indications for referral. Such a hypothesis leads us back to the point of view which sees variation in consultant opinion as the primary factor in differences in operation rates.

Somewhat surprisingly, the relationship between operation rates and organizational features of ENT practice has received little attention in the literature. If it is true that many predisposing conditions for adenotonsillectomy may be subject to spontaneous remission given time, one might expect that areas which combine a lengthy waiting list with facilities for the periodic review of waiting list cases may well 
TABLE III

ADENOTONSILLECTOMY RATES OF CHILDREN AGED UNDER 15 YEARS IN REGIONS OF SCOTLAND AND WAITING LIST TIME FOR OPERATION FOR THE YEAR

\begin{tabular}{|c|c|c|c|}
\hline Region & No. & $\begin{array}{l}\text { Rate } / 1,000 \\
\text { Children under } 15^{*}\end{array}$ & $\begin{array}{l}\text { Days on Waiting } \\
\text { List before Operation }\end{array}$ \\
\hline $\begin{array}{l}\text { North ... } \\
\text { North East } \\
\text { East .. } \\
\text { South East } \\
\text { West .. }\end{array}$ & $\begin{array}{r}357 \\
1,372 \\
1,426 \\
4,949 \\
13,197\end{array}$ & $\begin{array}{r}8 \cdot 8 \\
11 \cdot 9 \\
13 \cdot 9 \\
17 \cdot 8 \\
16 \cdot 7\end{array}$ & $\begin{array}{r}95 \cdot 5 \\
72 \cdot 7 \\
98 \cdot 3 \\
152 \cdot 9 \\
113 \cdot 3\end{array}$ \\
\hline
\end{tabular}

*Calculated from the 1966 sample census

have lower operation rates than areas with shorter waiting lists. However, lengthy waiting lists also reflect the unmet need for the operation-demand may be the highest where waiting lists are longest. Hence rates of operation may be highest where the waiting list is greatest. This is demonstrated in Table III.

Thus, it is clear that while Glover's hypothesis concerning the relationship of local medical opinion to local adenotonsillectomy rates has been supported by subsequent writers, the hypothesis has never been subjected to rigorous investigation. Additionally, both the nature of the parts played by GPs and otolaryngologists in producing these variations in operation rates and the relative importance of differences in the organization of ENT practice for the generation of regional differences remain unclear.

\section{VARIATION IN OPERATION RATE ACCORDING TO SOCIO-ECONOMIC Status}

Glover (1948) pointed out that considerable variation existed in the frequency of operation according to social class, the more prosperous classes being more prone to operation. That this phenomenon was not peculiar to the British is substantiated by the findings of Mertz (1954), who found similar variations in America. A possible reason for this (apart from the obvious one of the more affluent being better able to afford and thus obtain surgical treatment) is that parental pressure applied from members of the higher socio-economic groups will be more effective than that of the lower groups. Numerous other studies argue the importance of parental pressure (Fry, 1957; Bakwin, 1958; Miller, Court, Walton, and Knox, 1960; and Bolande, 1969). Parental pressure is also discussed in studies such as that of Furman (1959), in which he advises practitioners how to handle parental pressure for operations, and also that of Lipton (1962), in which he undertakes a Freudian analysis of the psychological basis of parental desire for tonsillectomy.
However, the concept of parental pressure requires further specification as it is at present illdefined. Does 'parental pressure' mean specific demands made by parents to have the operation performed, i.e., the parent having a well-defined aim in view and actively seeking to achieve it; or does it reflect the more diffuse concern of the parent for the child's well-being as manifest by the parental tendency to resort frequently to the family doctor? Such repeated demands on the family doctor constitute a form of parental pressure which could lead to the child being referred for operation more as an attempt by the doctor to be seen to be doing his therapeutic utmost rather than in the conviction of obtaining a worthwhile result.

It would appear that the proportion of parents making specific demands on the doctor is rather small. (It is not very clear from the literature whether pressure is thought to be exerted on both general practitioners and hospital consultants.) A study of all referrals by 30 general practitioners in southern England to all outpatient departments (Starey, 1961) found that only $4 \cdot 1 \%$ of all referrals were made as a result of pressure from the patient or a relative and in a similar study the figure was $2.3 \%$ (Oxford Regional Hospital Board Opera tional Research Unit, No. 3, 1963).

On the other hand, a degree of support for the view that 'parental pressure' consists merely of parental solicitude for the health of the child, and thus produces a higher propensity to consult the doctor, is provided by a recent study by Robinson (1971). Robinson found that mothers who felt that taking out uninfected tonsils was good for a child's general health were more likely to consult the doctor for relatively minor childhood ailments (loss of appetite, tummyache, etc.) than those mothers who only felt that taking out infected tonsils was good for a child's general health or mothers who felt that taking out the tonsils, infected or uninfected, was unlikely to improve a child's general health.

It is probable that the variation in operation rates between social classes is now insignificant in Britain since the advent of the National Health Service. Douglas and Blomfield (1958) found little difference in operation rates between the children of non-manuals and the children of skilled workers in their sample of pre-school children, although semiand unskilled workers' and agricultural workers' children were less likely to have undergone the operation. Recent analysis of data collected on 2,500 Aberdeen children under 15 in 1965 supports Douglas and Blomfield's findings on the reduced 
TABLE IV

SOCIAL CLASS DISTRIBUTION OF TONSILLECTOMIES IN CHILDREN UNDER 15 YEARS IN ABERDEEN IN 1965 (Based on figures obtained from G. W. Horobin)

\begin{tabular}{|c|c|c|c|c|c|}
\hline \multicolumn{2}{|c|}{ Social Class* } & Children Tonsillectomized & $\begin{array}{l}\% \text { Tonsillectomized } \\
\text { Children in Class }\end{array}$ & Children not Tonsillectomized & Total \\
\hline $\begin{array}{l}\text { Unclassified . } \\
\text { I } \ldots \\
\text { II }^{\prime} . \\
\text { IIIa }_{\text {IIIb }}^{\text {IIIc }} \\
\text { IV } \\
\text { V } \ldots\end{array}$ & 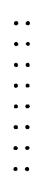 & $\begin{array}{r}19 \\
38 \\
127 \\
90 \\
167 \\
149 \\
98 \\
93\end{array}$ & $\begin{array}{l}18 \cdot 4 \\
34 \cdot 2 \\
33 \cdot 3 \\
31 \cdot 1 \\
32 \cdot 8 \\
32 \cdot 1 \\
32 \cdot 6 \\
27 \cdot 1\end{array}$ & $\begin{array}{r}84 \\
73 \\
254 \\
199 \\
342 \\
315 \\
202 \\
250\end{array}$ & $\begin{array}{l}103 \\
111 \\
381 \\
289 \\
509 \\
464 \\
300 \\
343\end{array}$ \\
\hline Total & . & 781 & $31 \cdot 2$ & 1,719 & 2,500 \\
\hline
\end{tabular}

*The distinction between social classes made here is based on information concerning the father's occupation and corresponds to that used by the Registrar-General except insofar as social class III is further subdivided. IIIa refers to those non-manual workers who fall into the RegistrarGeneral's social class III. IIIb refers to those skilled manual workers who work in trades with a formal apprenticeship requirement. IIIc refers to those skilled manuals whose trades do not have a formal apprenticeshilp system. The category 'unclassified' comprises children whose father's occupation was not known, children whose father was deceased, and children whose father was unemployed.

disparity in the operation rate between children from different socio-economic groups (Table IV).

The explanation that Douglas and Blomfield provide for their findings is consistent with our earlier discussion: ' $\ldots$ it appears that the popularity of this operation has already spread to the skilled and not to the unskilled manual or agricultural workers. At the same time its popularity appears to be declining in the non-manual groups' (Douglas and Blomfield, 1958, p. 93).

In other words, increasing doubts among members of the medical profession concerning the therapeutic value of indiscriminate operations for the removal of tonsils and adenoids may have been communicated to the non-manual sector of the population who are thus less anxious for their children to be operated upon. This knowledge has not, however, been communicated to manual workers and their wives who, when concerned about their children's health, are more likely to view tonsillectomy as a worthwhile undertaking. Support for such a hypothesis can be found in Robinson's study (1971): mothers who felt that removal of uninfected tonsils would be good for a child's general health were likely to have less formal education and have husbands of lower occupational status than mothers in the rest of the sample. Additional circumstantial support for this 'cultural lag' hypothesis was found by Douglas and Blomfield in their analysis of the chronological position of the tonsillectomized child in the family (Douglas and Blomfield, 1958, p. 143).

In sum then, parental pressure may remain an important phenomenon in the process leading to childhood tonsillectomy although its influence is no longer exclusively confined to the upper socioeconomic groups.

\section{CONCLUSION}

Our review of investigations has shown that no entirely satisfactory evaluative study exists. Each one that has been described has had major or minor defects. The fundamental problems in such studies are:

1. that it is unethical to establish valid contro groups-in effect to withhold the operation from children for whom the consultan considers it to be unequivocally desirable; and

2. that it is impossible to conceal from the parent or the doctor that the tonsils have been removed. This knowledge inevitably must colour both parental and medical interpretations of symptomatology and tends to vitiate postoperative assessment of illness.

Only approximations to the solutions of these problems are possible.

The ethical problem can to some extent be circumvented by establishing alternative ethical therapeutic procedures to the operation. What such alternatives might be is a matter of conjecture but it might be acceptable, for example, to offer chemoprophylaxis under bacteriological surveillance and advice for recurrent tonsillitis as an alternative to operation. Comparison of the relative merits of the alternative procedures may allow the decision to be reached as to what is the better course of treatment.

The second of our fundamental problems, that of bias in parental reportage of symptoms and of bias in the clinician's assessment of symptoms, is probably only amenable to partial resolution. The intrusion of bias into clinical assessments via the parental history can be said to involve two components. First, there is a perceptual component: parents 
who know that the tonsils have been removed may simply perceive less symptoms than their more anxious peers whose children's tonsils remain in situ, regardless of any objective differences in the symptomatology of the children in the two groups, and secondly, there is a communication component. A parent of an untonsillectomized child may or may not want to obtain an operation for the child and, depending upon his preferences, will present the child's history to the physician in such a way as to increase the chances of obtaining whichever treatment is desired.

It is undoubtedly true that the problems posed by both variations between parents in the perception of symptoms and by variations between parents in the communication of symptoms can be rendered somewhat less serious by greater recourse to objective bacteriological, virological, and immunological tests in clinical assessment. Such tests both reduce the clinician's reliance on the parental history and provide some yardstick for judging the accuracy of the parental history. Greater usage of such tests in evaluative studies may also provide a check on purely clinician bias in assessment.

Nevertheless it would be quite unwarranted to assume that more recourse to throat swabbing and other investigative procedures would eliminate the problem of bias among either parents or clinicians. Positive results from a throat swab may merely indicate the presence of bacteriological infection, and for evidence on the frequency and severity of such infections the clinician must turn once again to the parent.

However, it would be possible appreciably to diminish the effects of parental bias in the communication of the history (though not in the differential perception of symptoms by parents) if more were definitely known concerning the nature and content of communication between parent and clinician. More specifically, it should be possible to devise forms of questions which have the effect of providing clinicians with the symptomatic information they require for assessment while minimizing parental scope for colouring and distorting that information.

Communication between clinician and parent is best studied in a clinical situation and the authors are presently engaged in a detailed study of clinic practice as part of a sociological and epidemiological investigation of tonsillectomy. It is hoped that the findings of this detailed study will shed some light on the manifestation and control of parental bias.
We are indebted to many persons, particularly to $\mathrm{Mr}$. I. S. D. Thomson and Mr. C. D. Weir, with whom discussion has helped us clarify basic problems regarding adenotonsillectomy. Mr. Gordon Horobin kindly gave us access to the data from which Table IV was constructed. Dr. J. D. Donnelly, of the RIU of the Scottish Home and Health Department, has been consistently and kindly co-operative in providing us with Scottish national and regional data. The Medical Research Council has provided support for the study on adenotonsillectomy in which the authors are participating.

\section{REFERENCES}

Backett, E. M., Sumner, G., Kilpatrick, J., and DINGWALL-FORDYCE, I. (1966). Hospitals in the North-East Scotland Region. In: Problems and Progress in Medical Care, 2nd series, edited by G. McLachlan, p. 79. Nuffield Provincial Hospitals Trust, Oxford University Press, London.

BAKWIN, H. (1958). The tonsil-adenoidectomy enigma. J. Paediat., 52, 339.

BolandE, R. P. (1969). Ritualistic surgery-circumcision and tonsillectomy. New Engl. J. Med., 280, 591.

Celsus, A. C. (1938). Of Medicine, translated by W. G. Spencer, p. 371. Loeb Library Edition, Vol. 3, London.

Chief Medical Officer (1959). Report on the Health of the School Child 1957-8. HMSO, London.

Douglas, J. W. B. and Blomfield, J. M. (1958). Childrer Under Five. Allen and Unwin, London.

EPIDEMICS IN ScHoOLS (1938). By the Schools Epidemics Committee. Spec. Rep. Ser. med. Res. Coun. No. 227, p. 118.

Evans, H. E. (1968). Tonsillectomy and adenoidectomy; review of published evidence for and against the $T$ and A. Clin. Paediat., 7, 71.

Feinstein, A. R. and LevitT, M. (1970). The role of the tonsils in predisposing to streptococcal infections and recurrences of rheumatic fever. New Engl.J. Med., 282, 285.

Forsyth, G. and Logan, R. F. L. (1960). The Demand for Medical Care: a Study of the Caseload in the Barrow and Furness Group of Hospitals, p. 90. Nuffield Provincial Hospitals Trust, Oxford University Press, London.

FRY, J. (1957). Are all T's and A's really necessary? Brit. med. J., 1, 124.

FuRman, R. A. (1959). Handling parental pressure for T and A. J. Paediat., 54, 195.

Glover, J. A. (1938). The incidence of tonsillectomy in school children. Proc. roy. Soc. Med., 31, 1219.

(1948). The paediatric approach to tonsillectomy. Arch. Dis. Childh., 23, 1.

- and Wilson, J. (1932). The end-results of the tonsil and adenoid operation in childhood and adolescence. Brit. med. J., 2, 506.

ILLINGWORTH, R. S. (1939). Tonsillectomy and nephritis of childhood. Lancet, 2, 1013. 
(1961). The tonsillectomy problem. Proc. roy. Soc. Med., 54, 393.

KAISER, A. D. (1922). Effect of tonsillectomy on general health in five thousand children. J. Amer. med. Ass., 78, 1869.

(1931). Relation of tonsils and adenoids to infections in children based on a control study of four thousand four hundred children over a ten-year period. Amer. J. Dis. Child., 41, 568.

Lancet (1967). Editorial: Tonsillectomy, 2, 1292.

LAYTON, T. B. (1914). Tonsils and adenoids in children; a plea for fewer operations. Trans. med. Soc., Lond, 37, 244.

Levy, A. M., Tabakin, B. S., Hanson, J. S., and NARKewicz, R. M. (1967). Hypertrophied adenoids causing pulmonary hypertension and severe congestive heart failure. New Engl. J. Med., 277, 506.

Lipton, S. D. (1962). Psychology of childhood tonsillectomy. Psychoanal. Stud. Child, 17, 363.

Luke, M. J., Mehrizi, A., Folger, G. M. Jr., and Rowe, R. D. (1966). Chronic nasopharyngeal obstruction as a cause of cardiomegaly, cor pulmonale, and pulmonary edema. Pediatrics, 37, 762.

McCorkle, L. P., Hodges, R. G., Badger, G. F., Dingle, J. H., and JoRdan, W. S. Jr. (1955). Study of illness in a group of Cleveland families. VIII Relation of tonsillectomy to incidence of common respiratory diseases in children. New Engl. J. Med., 252, 1066.

MCKEE, W. J. E. (1963a). A controlled study of the effects of tonsillectomy and adenoidectomy in children. Brit. J. prev. soc. Med., 17, 49.

(1963b). The part played by adenoidectomy in the combined operation of tonsillectomy with adenoidectomy: the second part of a controlled study in children. Brit. J. prev. soc. Med., 17, 133.
Mawson, S. R., Adlington, P., and Evans, M. (1967). A controlled study evaluation of adeno-tonsillectomy in children. J. Laryng., 81, 777.

- - - and - (1968). A controlled study evaluation of adeno-tonsillectomy in children. Part II. J. Laryng., 82, 963.

MerTz, J. C. (1954). Tonsillectomy and respiratory illness in populations of two communities in New York state. Milbank mem. Fd Quart., 32, 5.

MEYER, W. (1870). On adenoid vegetations in the naso-pharyngeal cavity; the pr pathology, diagnosis, and treatment. Medico-Chirurg. Trans, 53, 191.

Miller, F. J. W., Court, S. D. M., Walton, W. S., and KNOX, E. G. (1960). Growing Up in Newcastle upon Tyne; a Continuing Study of Health and Illness in Young Children Within Their Families. Nuffield Foundation, Oxford University Press, London.

Noonan, J. A. (1965). Reversible cor pulmonale due to hypertrophied tonsils and adenoids: studies in two cases. Circulation, 32 (Suppl. 2), 164.

OXFord Regional Hospital BoARd: Operational Research UnIt No. 3 (1963). Hospital Outpatient Services, p. 17. Oxford Regional Hospital Board, Oxford.

Robinson, D. (1971). 'Becoming a patient': mothers' ideas about tonsillectomy. Med. Offr, 125, 37.

Roydhouse, N. (1969). A controlled study of adenotonsillectomy. Lancet, 2, 931.

Starey, C. J. H. (1961). A hospital outpatient referral survey. J. Coll. Gen. Pract. Thames Valley Faculty, 4, 214.

Wallace, H. L. and Smith, A. B. (1936). The effect of early tonsilleztomy on the incidence of acute rheumatism. Edinb. med. J., 43, 452. 